\title{
Title: A Meta-analysis and systemic review study: PCR to diagnose localized pulmonary and extra pulmonary Tuberculous Infections.
}

1. Yashika Sharma, Jinan University, P.R China

2. Anushree Kabiraj, Jinan University, P.R China

3. Khusboo Kanda, Jinan University, P.R China

4. Sanu Santosh, Jinan University, P.R China

5. Supriya Singh, Jinan University, P.R China

6. Arpita Dandapat, Jinan University, P.R China

7. * Dattatreya Mukherjee, Jinan University, P.R China

Corresponding Author: Dattatreya Mukherjee, MBBS Student, Jinan University, P.R China Dattatreyamukherjee4u@outlook.com

PREPRINT POSTED IN OSF

Conflict of Interest: No COI

Funding: No Funding is attached with this paper

License CC-4.0 International License

DOI: 10.31219/osf.io/thgcs

CITE THIS ARTICLE AS: Sharma, Y., Kaviraj, A., Kanda, K., Santosh, S., Singh, S., Dandapat, A., \& Mukherjee, D. (2021, March 22). A Meta-analysis and systemic review study: PCR to diagnose localized pulmonary and extra pulmonary Tuberculous Infections. Retrieved from osf.io/thgcs

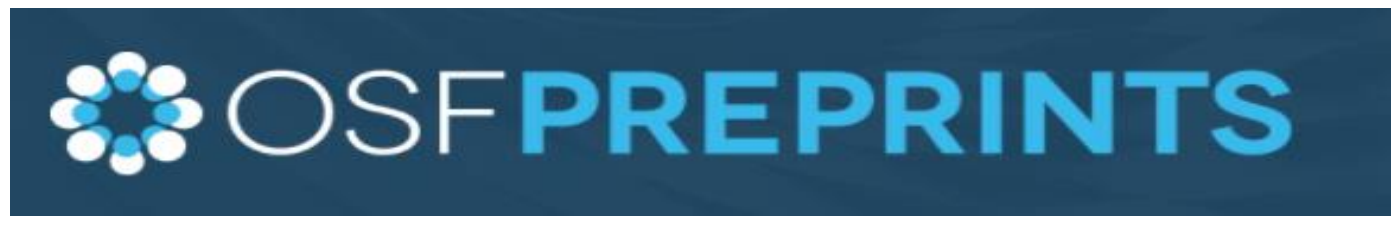


INDEX: 1. ABSTRACT

2.KEY WORDS

3.INTRODUCTION

4.REVIEW OF LITERATURE

5.DISCUSSION

6.CONCLUSION

7.MEDICAL DEVICES IN PRACTICE AND PATIENT SAFETY ASCERTAINED.

8.ACKNOWLEDGEMENTS

9.REFERENCES

\begin{abstract}
:
TB ranks as the second leading cause of death from an infectious disease worldwide. Rapid diagnosis and treatment are pivotal for the effective management and control of TB in clinical practice. However, the inherent limitations make it difficult to meet the requirement for early diagnosis. The Aim to this Metaanalysis study was to understand use of the polymerase chain reaction for the detection of Mycobacterium tuberculosis (TB PCR) as a basis for making diagnostic and clinical decisions and to understand sensitivity of TB PCR for the same. The aim to TB-PCR as a diagnostic tool is to rule out the other though efficient yet time consuming methods to diagnose Tb infections, as these methods delay the clinical decision making and further treatment.
\end{abstract}

KEYWORDS: TUBERCULOSIS(TB), PCR (POLYMERASE CHAIN REACTION), MULTIDRUGRESISTANCE INFECTIONS.

\title{
INTRODUCTION:
}

Tuberculosis (TB), is an infectious disease caused by the bacillus Mycobacterium tuberculosis (MTB), that spread from person to person predominantly through an airborne route. It remains a major global health problem as it causes ill-health among millions of people. After the human immunodeficiency virus (HIV), TB ranks as the second leading cause of death from an infectious disease worldwide [ $\underline{1}, \underline{2}]$. The lack of a simple and effective diagnostic test that can be utilised in resource-limited settings, where the infection is endemic, has hindered its control [3]. According to the World Health Organization in 2015, there were 10.4 
million new cases of TB worldwide that resulted in 1.8 million deaths and over $95 \%$ were from low- and middle-incomecountries[4, $\underline{5}]$.

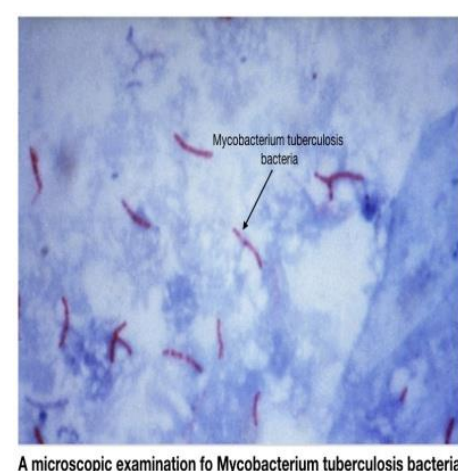

A microscopic examination fo Mycobacterium tuberculosis bacteria

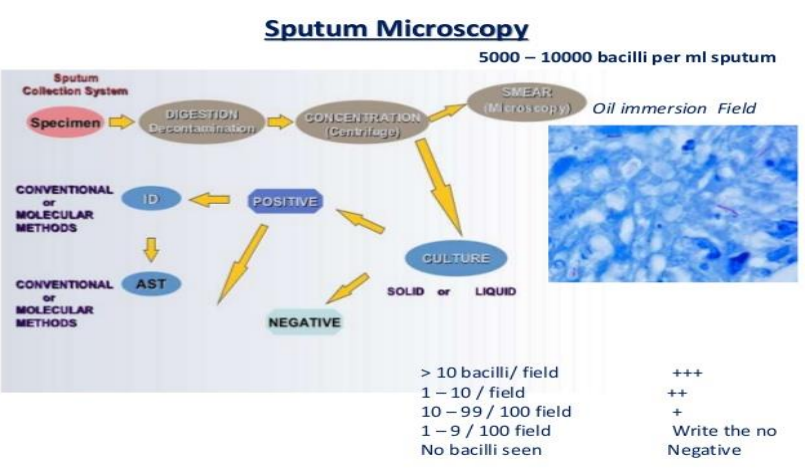

Fig 1: Sputum Microscopy

Generally, tuberculosis is diagnosed using the common conventional methods like sputum smear microscopy, chest radiographic findings and culture studies. Diagnosisof Mycobacteriumtuberculosis (MTB)infectionis madebyacid-fastbacillistainingandtheimprovedLöwenstein-Jensen(L-J)culturemethod. However,itistime-consuming, withtheresultsusuallyavailablein6-8weeks. Diagnoses involving radiological examinations and Tuberculin test help to detect the disease to some extent, but are not very reliable in case of extrapulmonary tuberculosis. The existing methodologies remain ineffective due to limitations because of low mycobacterium levels and/or time consuming procedures.

Non-MTB strains can also grow in the culture medium; therefore, it is necessary to perform the strain identification test to determine whether the strain growing is MTB or not.

Over the past decade, the TB diagnostics criterias have expanded, with several technologies showing promises [6]. In 1989, Hance et al. [7] firstly applied PCR for the detection of MTB. PCR has high sensitivity and specificity and is capable of detecting 1-100 fg of purified MTB DNA [8]. 


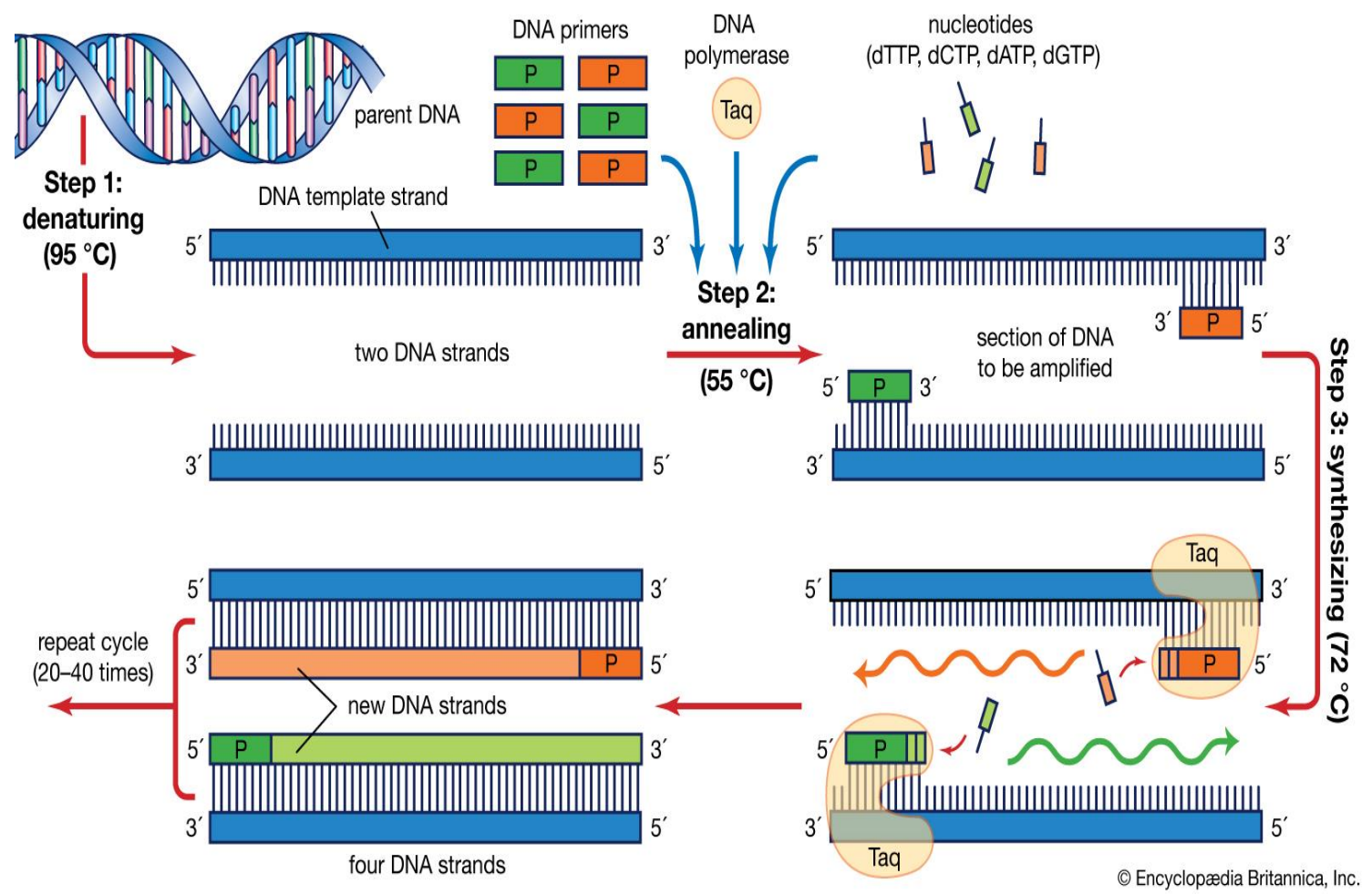

Fig 2: PCR

The conventional PCR technique is hardly effective because of false positives from amplified "contaminant" DNA. Real-time quantitative PCR (RT-qPCR) is the most commonly used quantitative PCR method, in which the PCR reaction is prepared with the addition of a specific fluorescent dye. Since its introduction in 1996, RT-qPCR has played a vital role in basic and applied research in life sciences [9, 10].Polymerase chain reaction has so far been a very useful tool for rapid detection of mycobacterial DNA in clinical specimens such as sputum, bronchial lavage, cerebrospinal fluid (CSF), and ascitic fluid. Definitive diagnosis of tuberculosis and mycobacterioses (nontuberculous mycobacteria (NTM) infections) has always been a serious problem. These methods also have their own limitations due to region-specific variations in the genome of mycobacteria $(11,12)$. Considering the increase in mycobacterial infections resulting from the emergence of NTM over the past decades, there is also need for a method that can detect virtually any deep-seated mycobacterial organism present in small numbers in suspected clinical samples irrespective of the mycobacterial species affiliation(13). 


\section{$\underline{\text { Review of literature of the articles describing utility and diagnostic efficacy of RT-PCR in }}$ evaluation of tuberculosis infection has been done.}

\section{REVIEW OF LITERATURE:}

Albuquerque YM et al (2014) [11]did prospective study to assess the accuracy of a diagnostic test, conducted on 140 sputum specimens from 140 patients living with HIV/AIDS with a clinical suspicion of PTB, attended at two referral hospitals for people living with HIV/AIDS in the city of Recife, Pernambuco, Brazil. A Löwenstein-Jensen medium culture and 7H9 broth were used as gold standard.Of the 140 sputum samples, 47 (33.6\%) were positive with the gold standard, q-PCR was positive in 42 (30\%) of the 140 patients. Only one $(0.71 \%)$ did not correspond to the culture. The sensitivity, specificity and accuracy of the q-PCR were $87.2 \%, 98.9 \%$ and $95 \%$ respectively. In 39 (93\%) of the 42 q-PCR positive cases, the CT (threshold cycle) was equal to or less than 37 . Their conclusion was that q-PCR performed on sputum smears from patients living with HIV/AIDS demonstrated satisfactory sensitivity, specificity and accuracy, and may therefore be recommended as a method for diagnosing PTB.

Antonenka $\mathrm{U}$ et al (2013) [12]tested 121 pre-characterized respiratory specimens (68 culture-positive for MTB complex, 24 culture-positive for non-tuberculousmycobacteria and 29 culture-negative) taken from their frozen specimen bank for the presence of MTB complex by the three assays.Among culture-positive samples $(n=68)$, overall sensitivity for detection of MTB complex was $74.6 \%, 73.8 \%$, and $79.1 \%$ for Xpert MTB/RIF, CTM-MTB, and DTB, respectively. Within the subgroup of smear-negative TB samples $(\mathrm{n}=51)$ sensitivity was $68 \%$ for Xpert MTB/RIF and CTM-MTB and $72 \%$ for DTB. Among smearpositive TB samples $(\mathrm{n}=17)$, all $(100 \%)$ were detected by DTB and $94.1 \%$ and $93.3 \%$ by Xpert MTB/RIF and CTM-MTB, respectively. Specificity was best for CTM-MTB (100\%) and lowest for Xpert MTB/RIF (96.2\%) due to misidentification of two NTM samples as MTB complex. CTM-MTB yielded the highest rate of invalid results $(4.1 \%)$ ( $0.8 \%$ by Xpert MTB/RIF and DTB, respectively).

They concluded that the direct comparison of Xpert MTB/RIF with CTM-MTB and DTB yielded similar overall performance data. Whereas DTB was slightly superior to Xpert MTB/RIF in terms of sensitivity, at least in the sample collection tested here, CTM-MTB performed best in terms of specificity.

Armand $S$ et al (2011) [13]compared the sensitivities of the Xpert MTB/RIF test and an in-house IS6110-based real-time PCR using TaqMan probes (IS6110-TaqMan assay) for the detection of Mycobacterium tuberculosis complex (MTBC) DNA by use of 117 clinical specimens (97 culture positive and 20 culture negative for MTBC) that were frozen in sediment. The 97 clinical specimens included 60 respiratory and 37 nonrespiratory specimens distributed into 36 smear-positive and 61 smear- 
negative specimens. Among the 97 culture-positive specimens, 4 had rifampin-resistant isolates. Both methods were highly specific and exhibited excellent sensitivity (100\%) with smear-positive specimens. The sensitivity of the Xpert MTB/RIF test with the whole smear-negative specimens was more reduced than that of the IS6110-TaqMan assay (48 versus $69 \%, \mathrm{P}=0.005$ ). Both methods exhibited similar sensitivities with smear-negative respiratory specimens, but the Xpert MTB/RIF test had lower sensitivity with smear-negative nonrespiratory specimens than the IS6110-TaqMan assay (37 versus $71 \%, \mathrm{P}=$ 0.013). Finally, the sensitivities of the Xpert MTB/RIF test and the IS6110-TaqMan assay were 79\% and $84 \%$, respectively, with respiratory specimens and $53 \%$ and $78 \%$, respectively $(\mathrm{P}=0.013)$, with nonrespiratory specimens. The Xpert MTB/RIF test correctly detected the rifampin resistance in smearpositive specimens but not in the one smear-negative specimen. Thet inferred that theXpert MTB/RIF test is a simple rapid method well adapted to a routine laboratory that appeared to be as sensitive as the IS6110-TaqMan assay with respiratory specimens but less sensitive with paucibacillary specimens, such as smear-negative nonrespiratory specimens.

Barletta F et al (2014) [14]optimized Real-time polymerase chain reaction (qPCR) for detecting Mycobacterium tuberculosis in sputum. Sputum was collected from patients $(\mathrm{N}=112)$ with suspected pulmonary tuberculosis, tested by smear microscopy, decontaminated, and split into equal aliquots that were cultured in Löwenstein-Jensen medium and tested by qPCR for the small mobile genetic element IS6110. The human ERV3 sequence was used as an internal control. 3 of 112 (3\%) qPCR failed. For the remaining 109 samples, qPCR diagnosed tuberculosis in 79 of 84 patients with culture-proven tuberculosis, and sensitivity was greater than microscopy (94\% versus $76 \%$, respectively, $\mathrm{P}<0.05$ ). The qPCR sensitivity was similar $(\mathrm{P}=0.9)$ for smear-positive $(94 \%, 60$ of 64) and smear-negative $(95 \%, 19$ of 20) samples. The qPCR was negative for 24 of 25 of the sputa with negative microscopy and culture (diagnostic specificity 96\%). The qPCR had 99.5\% sensitivity and specificity for 211 quality control samples including 84 non-tuberculosis mycobacteria. The qPCR cost $\sim 5$ US\$ per sample and provided same-day results compared with 2-6 weeks for culture.

Bloemberg GV et al (2013) [15] reported previously on the limited specificity of the CobasAmplicor MTB assay, in particular for positive samples with an optical density at $660 \mathrm{~nm}$ (OD660) of <2.0. Using a selected set of respiratory samples, which were scored as false positive by the CobasAmplicor test, we demonstrate here that the specificity of the CobasTaqMan assay is significantly improved. In addition, our study of a set of 133 clinical samples revealed that the CobasTaqMan MTB assay showed significantly less PCR inhibition than the CobasAmplicor test. An overall concordance of $98.2 \%$ was observed between the two assays. In a subsequent prospective study, we evaluated the performance of the Roche CobasTaqMan MTB assay on 1,143 clinical specimens, including respiratory $(n=838)$ and 
nonrespiratory $(\mathrm{n}=305)$ specimens. Using culture as the gold standard, we found a sensitivity of $88.4 \%$ and a specificity of $98.8 \%$ for the 838 respiratory specimens, compared to a sensitivity of $63.6 \%$ and a specificity of $94.6 \%$ for the 305 nonrespiratory specimens. They concluded that the CobasTaqMan MTB assay is a significantly improved tool for the direct detection of M. tuberculosis DNA in clinical specimens.

Chaidir L et al (2012) [16] examined Cerebrospinal fluid (CSF) samples using microscopy, solid and liquid culture, and real time IS6110-PCR with a fluorescence-labeled probe using DNA extracted from CSF. CSF samples from 40 non-infectious neurology patients were used as negative controls. IS6110PCR results were linked with clinical and CSF characteristics.Most patients presented with subacute meningitis, after a median of 14 days of symptoms (range 7-30). After exclusion of cryptococcal and bacterial meningitis, 207 patients were classified as definite or probable TB meningitis; $17.9 \%$ with HIV infection. Among this group IS6110-PCR gave the highest positivity rate $(68 \%, 95 \%$ CI $62-74 \%)$ compared with microscopy of $\mathrm{ZN}$-stained slides (11\%, 95\% CI 7-15\%), and mycobacterial culture using solid (36\%, 95\% CI 29-42\%) and liquid (44\%, 95\% CI 37-51\%) media. IS6110-PCR was positive in 92\% of patients with culture-positive and $42 \%$ of patients with culture-negative probable TB meningitis. Among culture-negative patients, a positive PCR was associated with a history of TB treatment, a longer duration of illness, a higher CSF cell count and protein, and a lower CSF glucose. IS6110-PCR was negative in all CSF samples from non-meningitis control patients. They concluded that Real time IS6110PCR is a quick, sensitive, and specific test for diagnosing of TB meningitis in this setting. Its performance in other (less-developed) settings needs further study.

Chang JH et al (2015) [17]retrospectively reviewed Real-time PCR assays using sputum specimens and/or bronchoscopic aspirates from 2,877 subjects; 2,859 subjects were enrolled. The diagnosis of TB was determined by positive microbiology, pathological findings of TB in the lung and pleura, or clinical suspicion of active TB following anti-TB medication for more than 6 months with a favorable response.Sensitivity, specificity, and accuracy were $44 \%, 99 \%$, and $86 \%$ from sputum, and $65 \%, 97 \%$, and $87 \%$ from bronchoscopic aspirates, respectively. For overall respiratory specimens, sensitivity was $59 \%$, specificity was $98 \%$, and accuracy increased to $89 \%$. Their conclusion was that the positivity in real-time PCR using any respiratory specimens suggests the possibility of active TB in clinically suspected cases, guiding to start anti-TB medication. Real-time PCR from selective bronchoscopic aspirates enhances the diagnostic yield much more when added to sputum examination.

Chen $X$ et al (2012) [18] collectedself-expectorated sputum for direct smear microscopy, culture, realtime PCR and AMTD assay. Performance of the 'Care TB' real-time PCR and AMTD assay were 
compared using a combination of culture and clinical diagnosis as a reference standard.Of the 178 sputum specimens, 83 were culture-positive; of these, 74 were Mycobacterium tuberculosis complex and 9 strains were non-tuberculousmycobacteria. The overall sensitivities and specificities were respectively $91.6 \%$ and $100 \%$ for real-time PCR, and $95.2 \%$ and $97.9 \%$ for AMTD. In the smear-positive specimens, the sensitivities and specificities were respectively $97 \%$ and $100 \%$ for real-time PCR, and $98.5 \%$ and $100 \%$ for AMTD. In the smear-negative specimens, the sensitivities and specificities were $70.6 \%$ and $100 \%$ for real-time PCR, and $82.4 \%$ and $97.7 \%$ for AMTD. They inferred that both real-time PCR and AMTD are rapid and specific tests for detecting $M$. tuberculosis complex; however, 'Care TB' real-time PCR is more convenient and economical.

Chitnis DS et al (2010) [19] assessed 204 cases: 50 were confirmed pleural TB, 104 were probable pleural TB, and 50 formed the non-TB group. IFN- $\gamma$ and IgA were measured by enzyme-linked immunosorbent assay and ADA was measured by colorimetric assay. Real-time PCR was carried out using the 16S rRNA sequence, pleural biopsy specimens were submitted to histopathologic examination, pleural fluid culture was undertaken using Lowenstein-Jensen and MGIT-BACTEC, and pleural fluid smears were stained with auramine O.For confirmed and probable pleural TB cases, the area under the curve (AUC) of the receiver operating characteristic (ROC) curve was highest for IFN- $\gamma(0.994$ and 0.963 , respectively), followed by ADA ( 0.989 and 0.945 , respectively), real-time PCR (0.898 and 0.784, respectively), and $\operatorname{IgA}(0.817$ and 0.784 , respectively). For confirmed and probable pleural TB cases, IFN- $\gamma$ showed the highest sensitivity ( $98 \%$ and $76.9 \%$, respectively), followed by ADA ( $92 \%$ and $73 \%$, respectively), real-time PCR (80\% and 57.7\%, respectively), and $\operatorname{IgA}$ (70\% and 57.7\%, respectively). With regard to combined positivity, the combination of 'either real-time PCR or IFN- $\gamma$ ' showed the highest sensitivity: $100 \%$ in confirmed pleural TB and $96.2 \%$ in probable pleural TB. They gave the conclusion that IFN- $\gamma$ showed the highest sensitivity as an individual diagnostic test. When a combination of tests was used, positivity of 'either IFN- $\gamma$ or real-time PCR' appeared valuable for the diagnosis of pleural TB.

Cho WH et al (2015) [20]mentioned thatAdvanSure tuberculosis/non-tuberculous mycobacterium (TB/NTM) PCR (LG Life Science, Korea) and COBAS TaqMan Mycobacterium tuberculosis (MTB) PCR (Roche Diagnostics, USA) are commonly used in clinical microbiology laboratories. They aimed to evaluate these two commercial real-time PCR assays for detection of MTB in a large set of clinical samples over a two-year period. AdvanSure TB/NTM PCR and COBAS TaqMan MTB PCR were performed on 9,119 (75.2\%) and 3,010 (24.8\%) of 12,129 (9,728 respiratory and 2,401 non-respiratory) MTB specimens, with 361 (4.0\%) and 102 (3.4\%) acid-fast bacilli (AFB)-positive results, respectively. In MTB culture, 788 (6.5\%) MTB and 514 (4.2\%) NTM were identified. The total sensitivity and specificity 
of the AdvanSure assay were 67.8\% (95\% confidence interval [CI], 63.9-71.6) and 98.3\% (95\% CI, 98.098.6), while those of the COBAS TaqMan assay were 67.2\% (95\% CI, 60.0-73.8) and 98.4\% (95\% CI, 97.9-98.9), respectively. The sensitivities and specificities of the AdvanSure and COBAS TaqMan assays for AFB-positive and AFB-negative samples were comparable. Furthermore, the AdvanSure assay showed fewer invalid results compared with the COBAS TaqMan assay (5.0 vs. 20.4 invalid results/1,000 tests, $\mathrm{P}<0.001)$. AdvanSure assay represents a comparable yet more reliable method than COBAS TaqMan for the identification of mycobacteria in routine clinical microbiology.

Iram Amin, Muhammad Idrees, Zunaira Awan,Muhammad Shahid, Samia Afzal, and Abrar Hussain(2011)(21): From 2004 to 2010 total 766 different types of smear negative samples from patients, clinically suspected for tuberculosis were received and investigated at Division of Molecular Diagnostics, University of the Punjab Lahore for the diagnosis of tuberculosis. Mycobacterial DNA was extracted followed by PCR amplification.

Findings: A total of 356 (46.5\%) samples were found positive by PCR for MTB. These included; serum (4.8\%), blood (36.3\%), urine (46.6\%), cerebro spinal fluid (CSF) (42.1\%), ascetic fluid (67.6\%), pleural fluid (52\%), pericardial fluid (30\%), pus (38.6\%), bone marrow (60\%), sputum (38.8\%) and bronchoalveolar lavage (BAL) (70\%). Over all there was no significant difference in males and females neither in different age groups for the identification of MTB.The conclusion drawn was that PCR is a useful and sensitive tool for the early diagnosis of MTB in variety of clinical samples.

\section{DISCUSSION:}

Tuberculosis is a global health threat and early and accurate diagnosis is crucial for preventing morbidity and mortality. Various methods are employed for the diagnosis of TB such as smear microscopy, culture identification, histopathology, tuberculin skin test (TST), serological assays, interferon-gamma release assays (IGRAs) and nucleic acid amplification (NAA) tests [22, 23]. Smear microscopy is widely used in the diagnosis of TB but has drawbacks owing to low and variable sensitivity values $(0-40 \%)$ and cannot readily differentiate between MTB and non-tuberculousmycobacteria (NTM) [24-26]. Culture identification for MTB also has variable sensitivities (0-80\%) in different TB specimens [21, 27-29] with turn-a-round time of 2-10 weeks requiring the use of skilful technicians [30]. Diagnosis of TB from tissue samples is usually made by histopathological examination that depends on the presence of granulomatous inflammation and caseous necrosis [24, 31]. However, histology does not distinguish between EPTB and infections from other granulomatous diseases such as NTM, sarcoidosis, leprosy and systemic lupus erythematosus (except for the presence of acid-fast bacilli (AFB)) [32, 33]. RT- 
PCR is a novel and robust assay primarily used to quantify the nucleic acids in all TB specimens

[21, 34-36]. The main advantages of RT-PCR are shortened turn-a-round time, quantification of bacterial load and automation of the procedure that reduces hands-on time and decreased risk of cross-contamination [21, 37].

\begin{tabular}{|c|c|c|c|c|c|} 
PCR STEPS & $\begin{array}{c}\text { Initial } \\
\text { Denaturation }\end{array}$ & Denaturation & Annealing & Extension & $\begin{array}{c}\text { Final } \\
\text { Extension }\end{array}$ \\
\hline Temperature & $\begin{array}{c}94 \text { degree } \\
\text { Celsius }\end{array}$ & $\begin{array}{c}94 \text { degree } \\
\text { Celsius }\end{array}$ & $\begin{array}{c}68 \text { degree } \\
\text { Celsius }\end{array}$ & $\begin{array}{c}72 \text { degree } \\
\text { Celsius }\end{array}$ & $\begin{array}{c}72 \text { degree } \\
\text { Celsius }\end{array}$ \\
\hline Time & $3 \mathrm{~min}$ & $45 \mathrm{~min}$ & $45 \mathrm{sec}$ & $50 \mathrm{sec}$ & $7 \mathrm{~min}$ \\
\hline & ------------ & ---------- & 25 cycle & ---------- & -----------
\end{tabular}

ART-

PCRassayforthedetectionofMTBhasahighsensitivityandspecificity. Thespecificitywashighforbothpulmon aryandextra-pulmonarysamplesindicatingthatthetestshouldbeadoptedasthefirst-

linetestforrulingoutordiagnosingTBinfectionbutmayneedtobeanadd-ontesttoruleoutthedisease.

It offers an alternative approach to detect MTB in paucibacillary EPTB samples, showing rapid results with good diagnostic accuracy. The results of this assay should be interpreted in parallel with clinical findings and the results of conventional tests, but the assay may contribute significantly for an early diagnosis and exert an impact on the clinical management and control of TB. The findings do not support the use of this assay for excluding a diagnosis of TB on its own as a standalone test. It offers an incremental benefit as an add-on test to other investigations. RT-PCR assays, combining amplification and detection in a single run, seem to offer advantages over conventional assays including the reference standard.

The advantage of TB PCR:

It is accurate conventional microscopic method.

$>$ A single bacterium can be detected.

$>$ Any sample can be used and detected with $100 \%$ accuracy.

$>$ The number of bacteria can also be quantified.

$>$ Decreases the TAT (turn around time).

\section{CONCLUSION:}

The TB PCR method is rapid, advance and accurate. The TAT can be maintained and the patient can be diagnosed in the early stage of the infection by TB PCR method. 
The multidrug-resistant TB infection however, cannot be precisely detected by the conventional TB PCR method.Real-time TB PCR assay is helpful in diagnosing Multidrug-resistant infections. Also, the turn around time is decreased by using the real-time assay.

\section{MEDICAL DEVICES IN PRACTICE AND PATIENT SAFETY ASCERTAINED:}

Our Aim through this paper was to ascertain the use, misuse and to analyse the lack of availability of medical devices in providing a better patient care and assuring patient safety at all goes. The ways devices are designed and used affect patient safety and quality of care: inappropriate design can provoke user error, create system vulnerabilities and divert attention from other aspects of patient care. Devices are playing an increasingly important role in the delivery of care, whether in monitoring vital signs, medication administration, analgesia or delivering specialist treatments. Appropriate implementation of medical devices regulation will enhance public health, patient safety, and the safety of health care professionals and environment.

Polymerase chain reaction is an indispensable tool in modern molecular biology, with extensive and enhanced improvement making it efficienctly vital to medical use. Using polymerase chain reaction as a method of diagnosis is not only highly sensitive and specific but also a less time consuming mode, thereby making it easier to reach diagnosis and make important clinical decisions in prcatice and provide better patient care.

\section{ACKNOWLEDGEMENTS:}

We are thankful to Dr.Ming Wai Kit Ming(M.D ,PhD, MPH, MMSc, EMBA, FRSPH), Jinan University, P.R China, for guiding us in this project.

\section{REFERENCES:}

1. Wallis RS, Pai M, Menzies D, Doherty TM, Walzl G, Parkins MD, et al. Biomarkers and diagnostics for tuberculosis: progress, needs and translation into practice. Lancet. 2010;375:19201937. 
2. Al-Ateah SM, Al-Dowaidi MM, El-Khizzi N. Evaluation of direct detection of Mycobacterium tuberculosis complex in respiratory and non-respiratory clinical specimens using the Cepheid Gene Xpert system. Saudi Med J. 2012;33:1100-1105.

3. Nikam C, Jagannath M, Narayanan MM, Ramanabhiraman V, Kazi M, Shetty A, et al. Rapid diagnosis of Mycobacterium tuberculosis with Truenat MTB: a near-care approach. PLoS One. 2013;8:e51121.

4. World Tuberculosis Day 2016: Unite to End Tuberculosis. http://www.afro.who.int/en/clusters-aprogrammes/dpc/tuberculosis/world-tuberculosis-day.html. Accessed 13 Dec 2016.

5. WHO Tuberculosis Global Report 2016. http://www.who.int/tb/Global_TB_Facts.pdf?ua=1. Accessed: 18 Oct 2016.

6. European Centre for Disease Prevention and Control . World Health Organization Regional Office Europe. Tuberculosis surveillance in Europe 2009. Stockholm: European Centre for Disease Prevention and Control; 2011.

7. A. J. Hance, B. Grandchamp, V. Lévy-Frébault et al., "Detection and identification of mycobacteria by amplification of mycobacterial DNA," Molecular Microbiology, vol. 3, no. 7, pp. 843-849, 1989.

8. R. J. Patel, J. W. U. Fries, W. F. Piessens, and D. F. Wirth, "Sequence analysis and amplification by polymerase chain reaction of a cloned DNA fragment for identification of Mycobacterium tuberculosis," Journal of Clinical Microbiology, vol. 28, no. 3, pp. 513-518, 1990.

9. C. B. Rees and W. Li, "Development and application of a real-time quantitative PCR assay for determining CYP1A transcripts in three genera of salmonids," Aquatic Toxicology, vol. 66, no. 4, pp. 357-368, 2004.

10. S. Rondini, E. Mensah-Quainoo, H. Troll, T. Bodmer, and G. Pluschke, "Development and application of real-time PCR assay for quantification of Mycobacterium ulcerans DNA," Journal of Clinical Microbiology, vol. 41, no. 9, pp. 4231-4237, 2003.

11. B. O'Shea, S. Khare, K. Bliss et al., "Amplified fragment length polymorphism reveals genomic variability among Mycobacterium avium subsp. paratuberculosis isolates," Journal of Clinical Microbiology, vol. 42, no. 8, pp. 3600-3606, 2004.

12. S. Homolka, S. Niemann, D. G. Russell, and K. H. Rohde, "Functional genetic diversity among Mycobacterium tuberculosis complex clinical isolates: delineation of conserved core and lineagespecific transcriptomes during intracellular survival," PLoS Pathogens, vol. 6, no. 7, Article ID e1000988, 2010 
13. Anamika Singh and Vijendra Kumar Kashyap Specific and Rapid Detection of Mycobacterium tuberculosis Complex in Clinical Samples by Polymerase Chain Reaction vol. 2012 Article ID 654694,2012

14. Albuquerque YMM, Lima ALMA, Lins AK, Magalhães M, Magalhães V. Quantitative real-time PCR (q-PCR) for sputum smear diagnosis of pulmonary tuberculosis among people with HIV/AIDS. Rev Inst Med Trop Sao Paulo. 2014;56:139-142.

15. Antonenka U, Hofmann-Thiel S, Turaev L, Esenalieva A, Abdulloeva M, et al. Comparison of Xpert MTB/RIF with ProbeTec ET DTB and COBAS TaqMan MTB for direct detection of $M$. tuberculosis complex in respiratory specimens. BMC Infect Dis. 2013;13:280-285.

16. Armand S, Vanhuls P, Delcroix G, Courcol R, Lemaître N. Comparison of the Xpert MTB/RIF test with an IS6110-TaqMan real-time PCR assay for direct detection of Mycobacterium tuberculosis in respiratory and nonrespiratory specimens. J ClinMicrobiol. 2011;49:1772-1776.

17. Barletta F, Vandelannoote K, Collantes J, Evans CA, Arévalo J, Rigouts L. Standardization of a TaqMan-based real-time PCR for the detection of Mycobacterium tuberculosis-complex in human sputum. Am Soc Trop Med Hyg. 2014;91:709-714.

18. Bloemberg GV, Voit A, Ritter C, Deggim V, Böttger EC. Evaluation of COBAS(R) TaqMan MTB for direct detection of Mycobacterium tuberculosis complex in comparison with the COBAS(R) Amplicor MTB. J ClinMicrobiol. 2013;51:2112-2117.

19. Chaidir L, Ganiem AR, van derZanden A, Muhsinin S, Kusumaningrum T, Kusumadewi I, et al. Comparison of real time IS6110-PCR, microscopy, and culture for diagnosis of Tuberculous meningitis in a cohort of adult patients in Indonesia. PLoS One. 2012;7:e52001.

20. Chang JH, Kim SW, Kim SI, Lee SJ, Lee JH, Ryu YJ, et al. The effectiveness of real-time PCR assay, compared with microbiologic results for the diagnosis of pulmonary tuberculosis. Tuber Respir Dis. 2015;78:1-7.

21. Chen X, Yang Q, Kong H, Chen Y. Real-time PCR and amplified MTD® for rapid detection of Mycobacterium tuberculosis in pulmonary specimens. Intern J Tuberc Lung Dis. 2012;16:235239.

22. Chitnis DS, Kalantri Y, Hemvani N. Evaluation of real-time polymerase chain reaction, interferongamma, adenosine deaminase, and immunoglobulin A for the efficient diagnosis of pleural tuberculosis. Intern J Infect Dis. 2010;15:e226-e231.

23. Cho WH, Won EJ, Choi HJ, Kee SJ, Shin JH, Ryang DW, et al. Comparison of AdvanSure TB/NTM PCR and COBAS TaqMan MTB PCR for detection of Mycobacterium tuberculosis complex in routine clinical practice. Ann Lab Med. 2015;35:356-361. 
24. Iram Amin, Muhammad Idrees, Zunaira Awan,Muhammad Shahid, Samia Afzal, and Abrar HussainPCR could be a method of choice for identification of both pulmonary and extra-pulmonary tuberculosis2011; 4: 332.

25. Seith S, Yadav R, Mewara A, Dhatwalia SK, Sharma M, Gupta D. Evaluation of in-house mpt64 real-time PCR for rapid detection of Mycobacterium tuberculosis in pulmonary and extrapulmonary specimens. Braz J Infect Dis. 2012;16:493-494.

26. Lange C, Mori T. Advances in the diagnosis of tuberculosis. Respirology. 2010;15:220-240.

27. Liu KT, WJ S, Perng RP. Clinical utility of polymerase chain reaction for diagnosis of smearnegative pleural tuberculosis. J Chin Med Assoc. 2007;70:148-151.

28. Haldar S, Bose M, Chakrabarti P, Daginawala HF, Harinath BC, Kashyap RS, et al. Improved laboratory diagnosis of tuberculosis — the Indian experience. Tuberculosis. 2011;91:414-426.

29. Derese Y, Hailu E, Assefa T, Bekele Y, Mihret A, Aseffa A, et al. Comparison of PCR with standard culture of fine needle aspiration samples in the diagnosis of tuberculosis lymphadenitis. $\mathrm{J}$ Infect Dev Ctries. 2012;6:53-57.

30. Padmavathy L, Rao L, Veliath A. Utility of polymerase chain reaction as a diagnostic tool in cutaneous tuberculosis. Indian J DermatolVenereolLeprol. 2003;69:214-216.

31. Sharma SK, Mohan A. Extrapulmonary tuberculosis. Indian J Med Res. 2004;120:316-353.

32. Takahashi T, Tamura M, Asami Y, Kitamura E, Saito K, Suzuki T, et al. Novel wide-range quantitative nested real-time PCR assay for Mycobacterium tuberculosis DNA: clinical application for diagnosis of tuberculous meningitis. J ClinMicrobiol. 2008;46:1698-1707.

33. Mehta PK, Kalra M, Khuller GK, Behera D, Verma I. Development of an ultrasensitive polymerase chain reaction amplified immunoassay (Immuno-PCR) based on mycobacterial RD antigens: implications for the serodiagnosis of tuberculosis. DiagnMicrobiol Infect Dis. 2012;72:166-174.

34. Almadi MA, Ghosh S, Aljebreen AM. Differentiating intestinal tuberculosis from Crohn's disease: a diagnostic challenge. Am J Gastroenterol. 2009;104:1003-1012.

35. Bravo FG, Gotuzzo E. Cutaneous tuberculosis. ClinDermatol. 2007;25:173-180.

36. Chawla K, Gupta S, Mukhopadhyay C, Rao PS, Bhat SS. PCR for M. Tuberculosis in tissue samples. J Infect Dev Ctries. 2009;3:83-87.

37. Petitti DB. Approaches to heterogeneity in meta-analysis. Stat Med. 2001;20:3625-3633.

38. Abbara A, Davidson RN. Etiology and management of genitourinary tuberculosis. Nat Rev Urol. 2011;8:678-688.

39. Baba K, Pathak S, Sviland L, Langeland N, Hoosen AA, Asjo B, et al. Real-time quantitative PCR in the diagnosis of tuberculosis in formalin-fixed paraffin-embedded pleural tissue in patients from a high HIV endemic area. Diagn Mol Pathol. 2008;17:112-117. 
40. Kalantri Y, Hemvani N, Chitnis DS. Evaluation of real-time polymerase chain reaction, interferongamma, adenosine deaminase, and immunoglobulin A for the efficient diagnosis of pleural tuberculosis. Intern. J Infect Dis. 2011;15:e226-e231.

41. Katoch VM. Newer diagnostic techniques for tuberculosis. Indian J Med Res. 2004;120:418-428. 